\title{
Sutureless Mastectomy Using Monopolar Electrocautery Only - A Report of 100 Consequent Cases
}

\author{
Omar Hamdy
}

Surgical Oncology Unit, Oncology Center, Mansoura University, Mansoura, Egypt

\section{ABSTRACT}

Background: Electrocautery has been used worldwide for performing MRM as it is associated with less blood loss, rapid operative time and cost-effectiveness with conflicting results about increased seroma formation. Its use is combined with ligation of the medium sized blood vessels from internal mammary artery and axillary vein.

Methods: 100 mastectomies was performed from June 2015 to April 2019 using monopolar electrocautery only for skin flaps elevation, axillary dissection and control of all included blood vessels as well as hemostasis

Results: The mean operative time was 45 minutes and the mean discharge date was one day while 83 patients had no complications, 14 patients had minor complications (seroma, slipped drain and wound dehiscence) and three patients had major complications; pulmonary embolism, reactionary bleeding as well as secondary bleeding.

Conclusions: Sutureless mastectomy using monopolar electrocautery only is a safe, costeffective and rapid technique which can be adopted for routine used in breast cancer operations.

Key words: breast neoplasms, axillary dissection, modified radical mastectomy

\section{INTRODUCTION}

Modified radical mastectomy (MRM) is still the most frequently performed surgical technique for management of operable breast cancer. Electrocautery has been used worldwide for performing MRM. It is associated with less blood loss, rapid operative time, cost-effectiveness with conflicting results about increased seroma formation (1-6). Classically, the technique is combined with ligation of medial perforators from the intermarry mammary artery as well as tributaries of the axillary vein (7-9).

\section{METHODS}

\section{Patients and preoperative preparation}

This series includes 100 female patients with operable breast cancer who were candidates for mastectomy. The patients were operated in surgical

\author{
Corresponding author: \\ Omar Hamdy, MD \\ Assistant lecturer of surgical oncology \\ Surgical Oncology Unit \\ Oncology center, Mansoura University \\ Mansoura, Egypt, postal code: 35516 \\ Phone number: +201003526752 \\ E-mail: omarhamdy87@gmail.com
}

Received: 21.10.2019

Accepted: 04.12.2019 
oncology unit, Oncology center, Mansoura University (OCMU), Egypt. All the patients were operated by the same surgeon from June 2015 to April 2019. All the patients underwent the routine preoperative preparation for breast cancer patients adopted in OCMU including bilateral sonomammography, preoperative biopsy, laboratory investigations and metastatic workup whenever indicated as well as preoperative anesthesiologist evaluation. All the patients were operated under general anesthesia and endotracheal intubation except one patient who was highly risky for general anesthesia so operated using regional anesthesia.

\section{SURGICAL TECHNIQUE: (FIGS. 1-10)}

After placing the patient in supine position with arm extension, skin sterilization and operative bed prepping, the operation starts by elliptical incision usually transverse - including the nipple areola complex and the biopsy scar. The skin flaps are made using electrocautery only in the avascular plane between the subcutaneous tissue and the breast tissue. Any bleeding point is held using non toothed forceps then cauterized. The borders of dissection are the parasternal line medially, the clavicle superiorly, the anterior border of Latissimus muscle laterally and the rectus sheath inferiorly. After skin flaps elevation, the breast is dissected from the underlying pectoralis major using electrocautery. Medially, the internal mammary perforators are held either by non-toothed dissecting forceps or small artery forceps and cauterized in-situ. Upon reaching the lateral border of pectoralis, the clavipectoral fascia is sharply divided using electrocautery, the lateral border of pectoralis minor is followed cranially till the axillary vein is reached, the fascia surrounding the vein is sharply divided as well as the fatty tissue at the lateral part of the axillary, then combined blunt and sharp evacuation of the axillary fat is performed using electrocautery which is used as well to control any bleeding points. The axillary vein tributaries - even the first tributary off the axillary vein - is hold by two dissecting or artery forceps, divided and then the proximal stump is cauterized. The long thoracic nerve, thoracodorsal bundle, pectoral vessels as well as the intercostobrachial nerve if possible - are preserved. After removal of the breast and axilla, adequate hemostasis is performed using electrocautery. Placement of suction drain $(18 ")$ is done then skin closure is performed using either prolene $2 / 0$ or skin stapler.

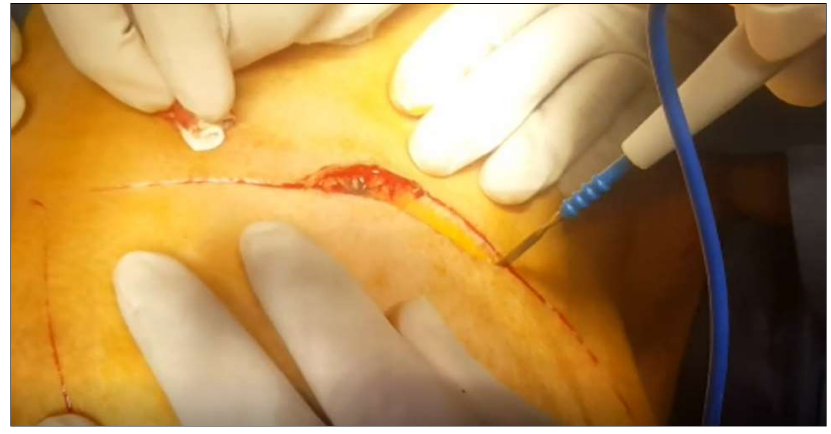

Figure 1 - Upper skin flap incision

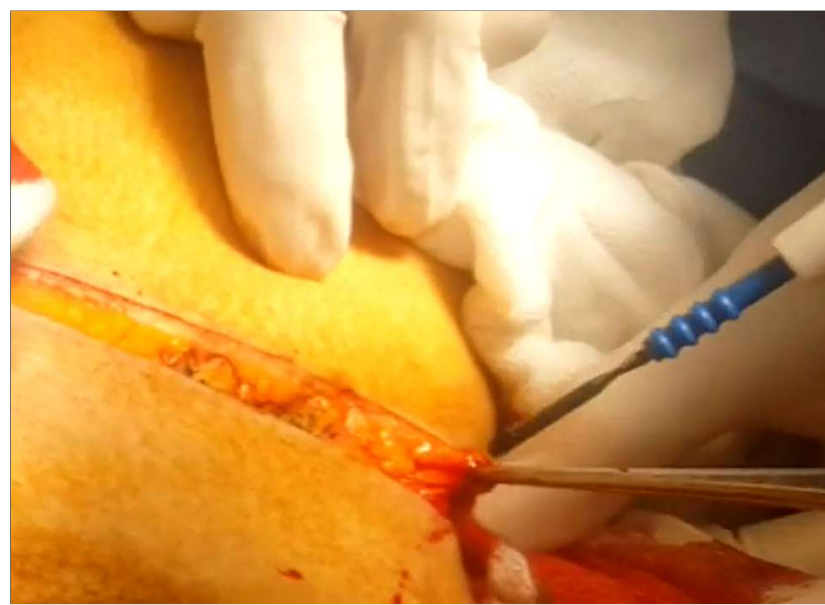

Figure 2 - Use of electrocautery to control a blood vessel in the subcutaneous tissue

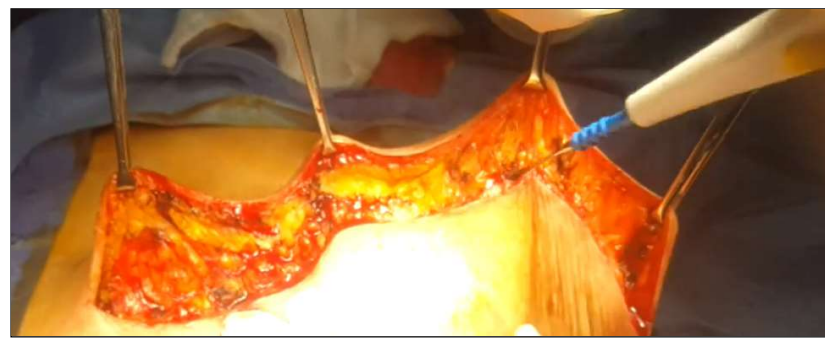

Figure 3 - Upper skin flap dissection using electrocautery in the plane between the subcutaneous tissue $\&$ the breast tissue

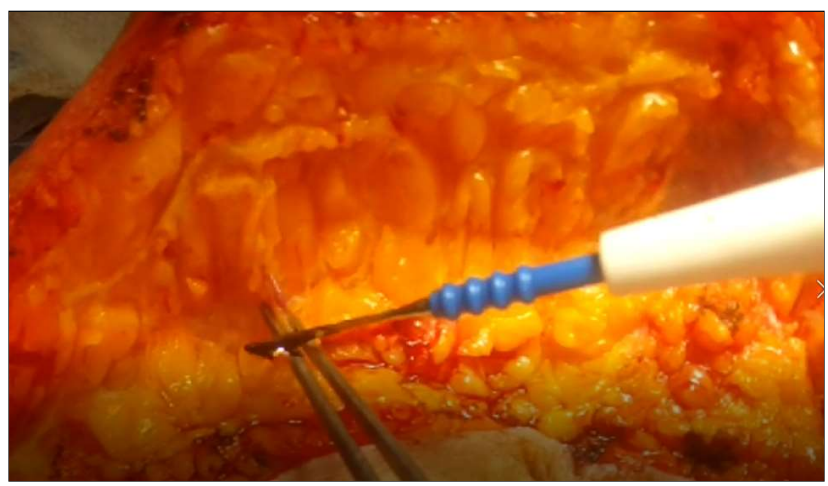

Figure 4 - Use of electrocautery to control a blood vessel in the upper flap 


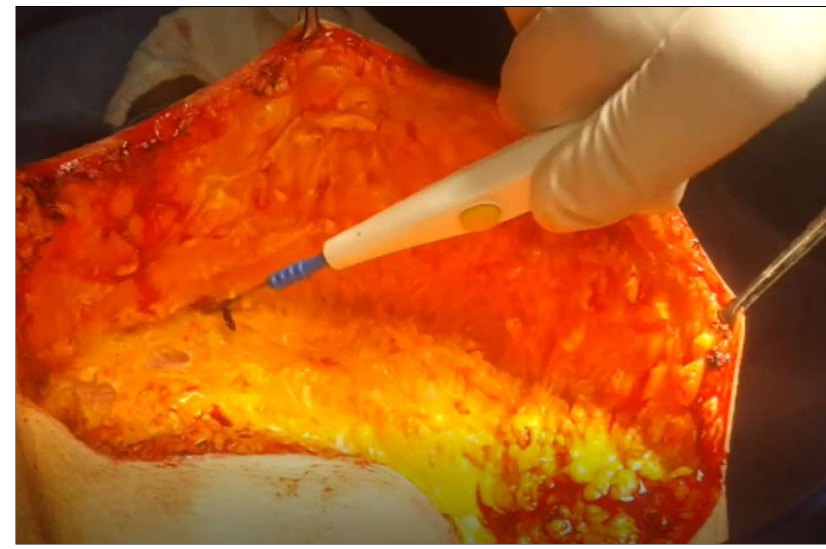

Figure 5 - Completion of upper flap dissection without any sutures or sealing device

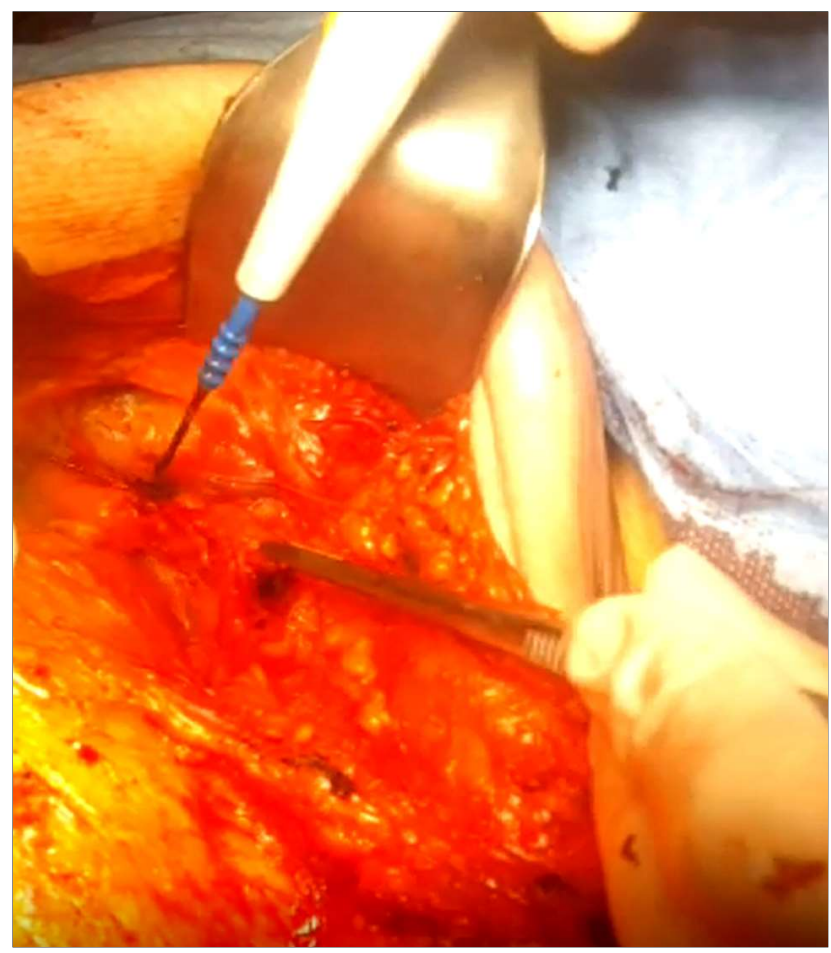

Figure 7 - Separation of the medial axillary lymph nodes group

\section{Postoperative management}

The patient is usually discharged after 24 hours unless there are any adverse events or needed medical monitoring for any associated co-morbidity. Stitches are removed within 14 days and the drain is removed if the output is less than $30 \mathrm{cc} / 24$ hours, typically within $14-21$ days.

\section{RESULTS}

One hundred female patients were included in this series. The mean age was 55 (35-87) years. 58 patients

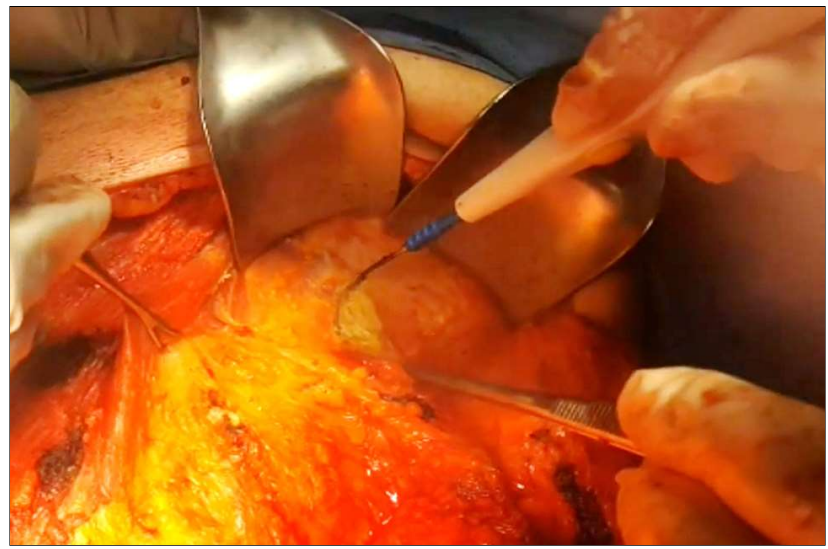

Figure 6 - Using electrocautery to gain access to the axilla via division of the clavicpectoral fascia

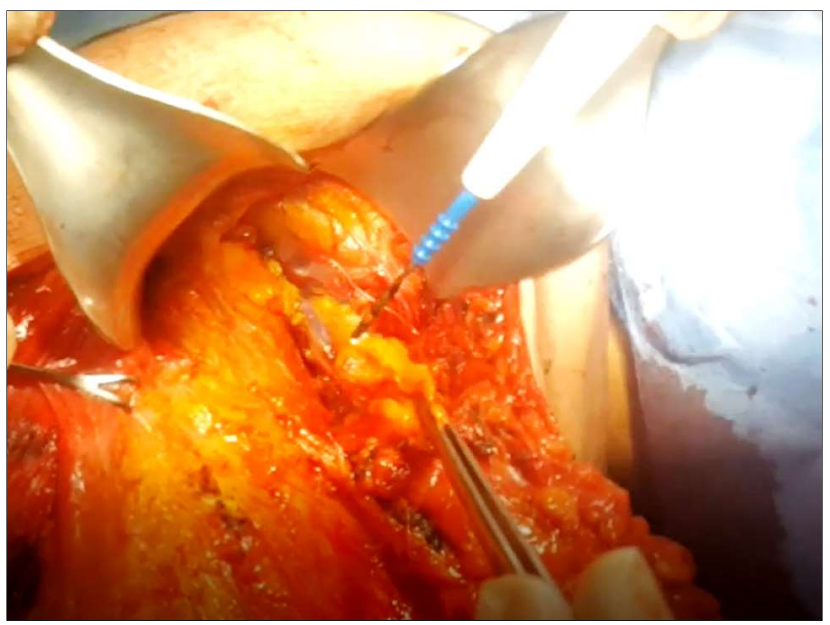

Figure 8 - Separation of the axillary lymph nodes from a tributary of the axillary vein using electrocautery

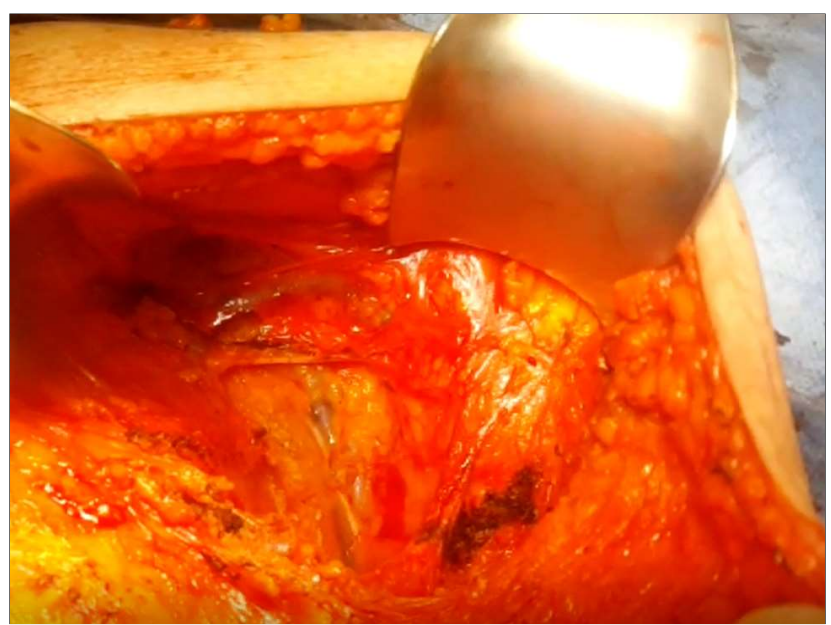

Figure 9 - The axilla after removal of level I \& II lymph nodes

had no medical comorbidities. The pathological type was infiltrating duct carcinoma in 91 patients. 46 


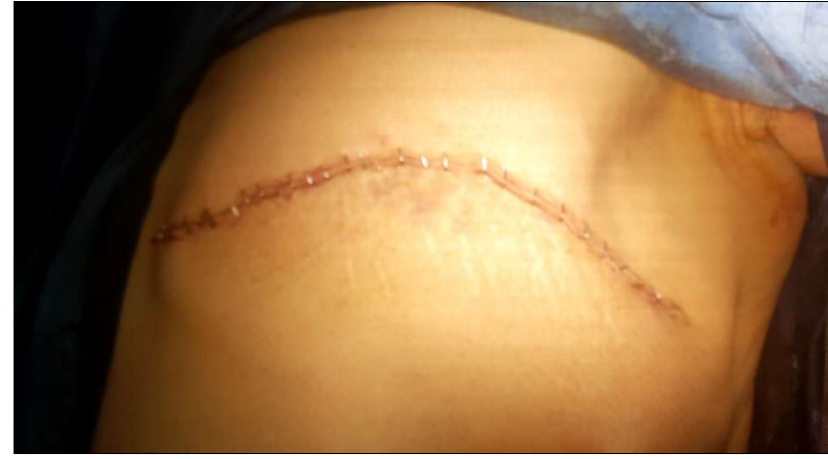

Figure 10 - Final result after skin closure by staples

patients received preoperative systemic therapy. The demographic and clinical data are available in table 1.

The operative procedure done was modified radical mastectomy in 79 patients and simple mastectomy in 21 patients. Out of those 21 patients, sentinel lymph node biopsy was performed in 17 patients while no axillary staging was performed in 4 patients. General anesthesia was used in 99 patients while regional anesthesia (combined serratus anterior plane block and paravertebral anesthesia) was used only in one patient. The mean operative time was 45 (25-90) minutes. Most patients (86\%) were discharged after 24 hours. The mean time for drain removal was 18 days.

83 patients did not develop postoperative complications and the postoperative course was uneventful. 17 patients developed complications; nine patients developed recollecting seroma after drain removal, 4 patients had wound dehiscence, while one patient's drain slipped earlier than planned.

Three patients only had major complications; one patient suffered from pulmonary embolism on the second postoperative day. Anticoagulant therapy was started immediately. The patient was discharged after one week after INR level reached the target level (2-3). Two patients developed postoperative bleeding; the

Table 1 - Clinical and demographic data

\begin{tabular}{|c|c|c|}
\hline \multicolumn{2}{|c|}{ Variable } & \multirow{2}{*}{$\begin{array}{c}\text { Number } \\
100\end{array}$} \\
\hline Number of patients & & \\
\hline Age & & $55.05(35-87)$ \\
\hline \multirow[t]{12}{*}{ Medical comorbidities } & None & 58 \\
\hline & Diabetes Miletus & 5 \\
\hline & Hypertension & 17 \\
\hline & cardiac disease & 3 \\
\hline & Chronic liver disease & 3 \\
\hline & Chest disease & 1 \\
\hline & hypothyroidism & 1 \\
\hline & Diabetes+ Hypertension & 6 \\
\hline & Diabetes + rheumatoid arthritis & 1 \\
\hline & Hypertension + chest disease & 2 \\
\hline & Hypertension + other cardiac disease & 1 \\
\hline & Diabetes + Hypertension + other cardiac disease & 2 \\
\hline \multirow[t]{6}{*}{ Pathology } & DCIS & 2 \\
\hline & IDC & 91 \\
\hline & ILC & 2 \\
\hline & Mucinous & 2 \\
\hline & Papillary & 2 \\
\hline & Metaplastic & 1 \\
\hline \multirow[t]{5}{*}{ Molecular subtype } & Luminal A & 33 \\
\hline & Luminal B & 40 \\
\hline & Triple negative & 15 \\
\hline & Her2-enriched & 11 \\
\hline & $\mathrm{N} / \mathrm{A}$ & 1 \\
\hline \multirow[t]{11}{*}{ Preoperative TNM } & $\mathrm{Tx}$ & 7 \\
\hline & Tis & 3 \\
\hline & $\mathrm{T} 1$ & 11 \\
\hline & $\mathrm{T} 2$ & 55 \\
\hline & T3 & 2 \\
\hline & $\mathrm{T} 4$ & 22 \\
\hline & NO & 37 \\
\hline & N1 & 60 \\
\hline & N2 & 3 \\
\hline & MO & 95 \\
\hline & M1 & 5 \\
\hline \multirow[t]{2}{*}{ Preoperative systemic therapy } & Yes & 46 \\
\hline & No & 54 \\
\hline
\end{tabular}


first was at zero-day postoperative. She underwent surgical evacuation of large hematoma with no detectable source of active bleeding apart from oozing raw surface of muscles. The second was at the eleventh postoperative day when the patient was readmitted from the hospital emergency department with sudden expanding hematoma. Immediate resuscitation was performed and surgical exploration of the operative bed revealed active bleeding from an internal mammary perforator which was controlled. The patient was discharged after 48 hours with no further adverse events.

The patients' operative data are collected in table 2.

\section{DISCUSSION}

Modified radical mastectomy is still the most common surgical technique used for the management of operable breast cancer (2). It includes resection of the mammary gland as well as level I\&II axillary lymph nodes with preservation of the pectoralis major muscle. The operation is usually performed under general anesthesia (8). Tumescent anesthesia has been described as a successful alternative as well (10). Electrocautery is used world- wide for flap elevation and hemostasis since it was recommended by Karlos \& James in $1970(3,11)$.

The patient is placed in supine position at the table edge with arm extension. Then skin sterilization and surgical field preparation is performed. The skin incision is performed including the nipple \& areola complex as well as the biopsy scar, usually starting with the upper skin flap using electrocautery. While the assistant is providing counter-traction, the surgeon incises the skin in a perpendicular plane to the subcutaneous tissue with preservation of skin thickness at about 4 to 8 millimeters according to the body weight. The limits of resection are the parasternal line medially, the anterior border of Latissimus Dorsi muscle laterally, the clavicle superiorly and the rectus sheath inferiorly. Separation of the mammary gland from the pectoralis major follows skin flaps dissection. Special care should be paid to the medial perforators originating from the internal mammary artery. Those vessels are usually ligated, clipped, controlled by harmonic scalpel or clamped and divided. In this series, those vessels were usually cauterized. Axillary dissection follows the mastectomy either from medial to lateral or from lateral to medial. All the loose areolar tissue including the axillary lymph nodes caudal to the axillary vein should be removed

Table 2 - Operative \& perioperative data

\begin{tabular}{|c|c|c|}
\hline Operation type & $\begin{array}{l}\text { Modified radical mastectomy } \\
\text { Simple mastectomy }\end{array}$ & $\begin{array}{l}79 \\
21\end{array}$ \\
\hline Axillary staging & $\begin{array}{c}\text { Axillary dissection } \\
\text { Sentinel lymph node biopsy } \\
\text { Not done }\end{array}$ & $\begin{array}{c}79 \\
17 \\
4\end{array}$ \\
\hline Anesthesia & $\begin{array}{l}\text { General } \\
\text { Regional }\end{array}$ & $\begin{array}{c}99 \\
1\end{array}$ \\
\hline Operative time & $\begin{array}{c}\text { Mean } \\
\leq 30 \\
31-45 \\
46-60 \\
61-90\end{array}$ & $\begin{array}{c}45(25-90) \\
28 \\
37 \\
31 \\
4\end{array}$ \\
\hline Hospital stay & $\begin{array}{c}\text { Mean } \\
1 \\
2 \\
3 \\
4-8\end{array}$ & $\begin{array}{c}1.25(1-8) \\
86 \\
6 \\
4 \\
4\end{array}$ \\
\hline Drain removal time & $\begin{array}{c}\text { Mean } \\
7-10 \\
11-14 \\
15-21 \\
22-30 \\
30-60\end{array}$ & $\begin{array}{c}18(7-60) \\
14 \\
16 \\
43 \\
22 \\
4\end{array}$ \\
\hline Postoperative complications & $\begin{array}{c}\text { No } \\
\text { Yes } \\
\text { Seroma after drain removal } \\
\text { Wound dehiscence } \\
\text { Slipped drain } \\
\text { Bleeding } \\
\text { Pulmonary embolism }\end{array}$ & $\begin{array}{l}83 \\
17 \\
9 \\
4 \\
1 \\
2 \\
1\end{array}$ \\
\hline
\end{tabular}


using scalpel or scissors after visualization of the axillary vein by dividing the deep layer of the superficial fascia in the axilla. The axillary vein tributaries are classically ligated, clipped or clamped and divided. Those vessels were usually cauterized in this series as well. The pectoral nerves, long thoracic nerve, nerve to Latissimus as well as the intercostobrachial nerve should be preserved. After completion of mastectomy and ALND, meticulous hemostasis should be performed followed by drain insertion and skin closure $(7-9,12)$.

What is new in the technique presented in this manuscript is depending totally on electrocautery in dissecting the flaps, separating the breast from the pectroalis major, removal of the axillary contents, hemostasis and - notably - in controlling internal mammary perforators and axillary vein tributaries which were classically considered too large to be cauterized (7). Those vessels were successfully controlled with cautery only in this series with neither collateral damage of the originating vessels nor postoperative bleeding events from those vessels. The bleeding which occurred in one patient from an internal mammary perforator was in the eleventh postoperative day, so it can be considered as secondary hemorrhage which is not related to technical factors. Rate of postoperative complications including seroma formation is within accepted range while the operative time is much less than the classic technique $(2,13,14)$

\section{CONCLUSION}

Sutureless mastectomy using monopolar electrocautery only is a safe, cost-effective and rapid technique which can be adopted for routine used in breast cancer operations.

Further randomized controlled trials should be conducted out to comment on other variables such as exact intraoperative blood loss, total drain output, postoperative pain as well as lymphedema

\section{Conflict of Interest}

The author declares he has no conflict of interest.

\section{Ethical Consideration}

All procedures performed in the study involving human participants were in accordance with the ethical standards of the institutional research committee and with the 1964 Helsinki declaration and its later amendments or comparable ethical standards.

\section{Availability of data and materials}

All the clinical, radiological \& pathological data used in this manuscript is available on Mansoura University database medical system (Ibn Sina Hospital management system). http://srv137.mans.edu.eg/mus/newSystem/

\section{Disclosures and funding source}

The author declares no conflict of interest. No funding source.

\section{REFERENCES}

1. Galatius $\mathrm{H}$, Okholm M, Hoffmann J. Mastectomy using ultrasonic dissection: effect on seroma formation. The Breast [Internet]. 2003; 12(5):338-41.

2. Khan S, Khan S, Chawla T, Murtaza G. Harmonic Scalpel Versus Electrocautery Dissection in Modified Radical Mastectomy: A Randomized Controlled Trial. Ann Surg Oncol [Internet]. 2014;21(3):808-14.

3. Anlar B, Karaman N, Dogan L, Ozaslan C, Atalay C, Altinok M. The effect of harmonic scalpel, electrocautery, and scalpel use on early wound complications after modified radical mastectomy. Eur Surg [Internet]. 2013;45(6):286-90.

4. Rodd CD, Velchuru VR, Holly-Archer F, Clark A, Pereira JH. Randomized Clinical Trial Comparing Two Mastectomy Techniques. World J Surg [Internet]. 2007;31(6):1166-70.

5. Mittal P, Kumar A, Kaur S, Pandove PK, Singla RL, Singh J. A Comparative Study of the Use of Harmonic Scalpel versus Unipolar Cautery in Modified Radical Mastectomy. Niger J Surg Off Publ Niger Surg Res Soc. 2017;23(1):20-5.

6. Porter K, O'Connor S, Rimm E, Lopez M. Electrocautery as a factor in seroma formation following mastectomy. Am J Surg [Internet]. 1998 Jul 1;176(1):8-11.

7. Bland KI. Modified Radical Mastectomy and Radical Mastectomy. In: Fischer JE, editor. Fischer's Mastery of Surgery. 7th editio. Wolters Kluwer; 2019. p. 2022-85.

8. Bland KI, Chang HR, Copeland EM. Modified Radical Mastectomy and Simple Mastectomy. In: Bland KI, Copeland EM, Klimberg VS, Gradishar WJBT-TB (Fifth E, editors. Elsevier; 2018. p. 443-461.e3.

9. Skandalakis LJ, Skandalakis JE. Breast BT. Surgical Anatomy and Technique: A Pocket Manual. In: Skandalakis LJ, Skandalakis JE, editors. New York, NY: Springer New York; 2014. p. 91-112.

10. Carlson GW. Total Mastectomy Under Local Anesthesia: The Tumescent Technique. Breast J [Internet]. 2005 Mar 1;11(2):100-2.

11. Kakos GS, James AG. The use of cautery in "bloodless" radical mastectomy. Cancer. 1970;26(3):666-8.

12. Fraterelli MC. Modified Radical Mastectomy. In: Hoballah JJ, ScottConner MD CEH, editors. Operative Dictations in General and Vascular Surgery [Internet]. New York, NY: Springer New York; 2012. p. 533-7.

13. Osman F, Saleh F, Jackson TD, Corrigan MA, Cil T. Increased Postoperative Complications in Bilateral Mastectomy Patients Compared to Unilateral Mastectomy: An Analysis of the NSQIP Database. Ann Surg Oncol [Internet]. 2013;20(10):3212-7.

14. Sampathraju S, Rodrigues G. Seroma Formation after Mastectomy: Pathogenesis and Prevention. Indian J Surg Oncol [Internet]. 2010; 1(4):328-33. 